Provided for non-commercial research and education use. Not for reproduction, distribution or commercial use.

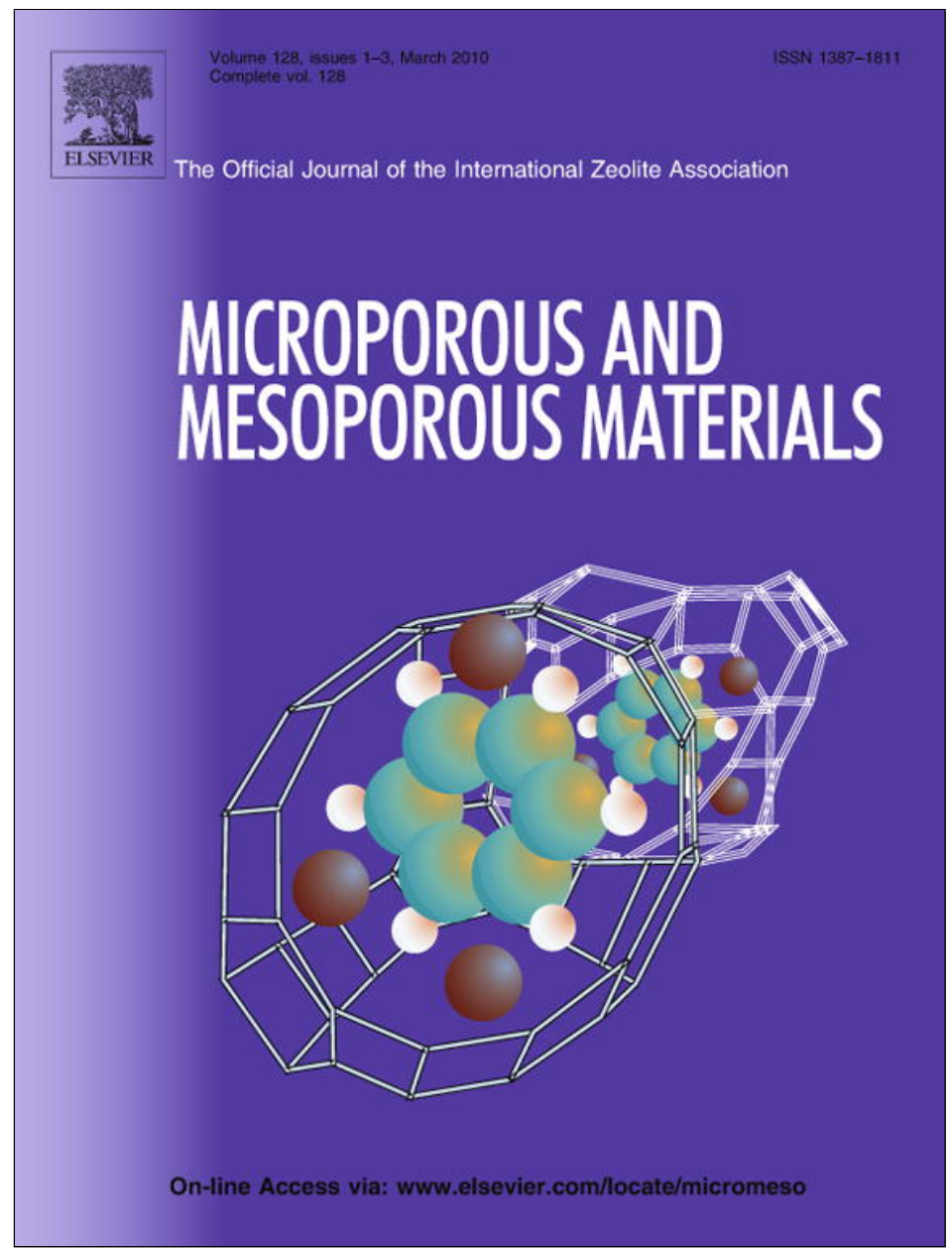

This article appeared in a journal published by Elsevier. The attached copy is furnished to the author for internal non-commercial research and education use, including for instruction at the authors institution and sharing with colleagues.

Other uses, including reproduction and distribution, or selling or licensing copies, or posting to personal, institutional or third party websites are prohibited.

In most cases authors are permitted to post their version of the article (e.g. in Word or Tex form) to their personal website or institutional repository. Authors requiring further information regarding Elsevier's archiving and manuscript policies are encouraged to visit:

http://www.elsevier.com/copyright 


\title{
Zeolite Beta membranes for the separation of hexane isomers
}

\author{
Patrick S. Bárcia ${ }^{\mathrm{a}, \mathrm{b}, *}$, Alexandre Ferreira ${ }^{\mathrm{c}}$, Jorge Gascon ${ }^{\mathrm{c}, *}$, Sonia Aguado ${ }^{\mathrm{c}}$, \\ José A.C. Silva ${ }^{\mathrm{a}}$, Alírio E. Rodrigues ${ }^{\mathrm{b}}$, Freek Kapteijn ${ }^{\mathrm{c}}$ \\ ${ }^{a}$ Escola Superior de Tecnologia e Gestão, Instituto Politécnico de Bragança, Apartado 1134, 5301-857 Bragança, Portugal \\ ${ }^{\mathrm{b}}$ Laboratory of Separation and Reaction Engineering, Departamento de Engenharia Química, Faculdade de Engenharia, Universidade do Porto, \\ Rua do Dr. Roberto Frias, S/N 4200-465 Porto, Portugal \\ ${ }^{c}$ Catalysis Engineering, DelftChemTech, Delft University of Technology, Julianalaan 136, 2628 BL Delft, The Netherlands
}

\section{A R T I C L E I N F O}

\section{Article history:}

Received 7 July 2009

Received in revised form 21 August 2009

Accepted 22 August 2009

Available online 27 August 2009

\section{Keywords:}

Zeolite Beta membranes

Vapour permeation

Branched hexane

Mixture permeation

Separation factor

\begin{abstract}
A B S T R A C T
The preparation of $\alpha$-alumina supported zeolite Beta membranes was successfully achieved and sped up by exploring combinations of three seeding techniques and three synthetic methods. The surface of the membranes was completely covered by well intergrown crystals; the thickness of the zeolite layers ranged from 2 to $6 \mu \mathrm{m}$ depending on the synthesis method used. The quality of the membranes was tested by means of pervaporation of ethanol/1,3,5-triisopropylbenzene (TIPB) mixtures together with permporometry experiments. The performance in the vapour separation of quaternary equimolar mixtures of $n$ hexane ( $n$ HEX), 3-methylpentane (3MP), 2,3-dimethylbutane (23DMB) and 2,2-dimethylbutane (22DMB) in the range 343-443 K showed that permeate flux decreases as the branching degree increases following the order: $n \mathrm{HEX} \gg 3 \mathrm{MP}>23 \mathrm{DMB}>22 \mathrm{DMB}$. In the retentate, the fractions of monobranched and normal hexane decrease while the concentration of dibranched isomers is increased compared to the feed composition. The influence of the temperature in the permeation fluxes indicates the existence of an activated transport mechanism which favours the permeation of more $n \mathrm{HEX}$ and $3 \mathrm{MP}$ with regard to their dibranched isomers. The octane number $(\mathrm{ON})$ of the quaternary mixture was enhanced up to 5 points with the best synthesized membrane.
\end{abstract}

(c) 2009 Elsevier Inc. All rights reserved.

\section{Introduction}

Hydroisomerization of light paraffins is a major process in the oil refinery and has been studied widely. The isomerization process is performed to increase the octane rating of low-grade linear alkanes (pentane to octane fraction). The isomerization of $n$-hexane (nHEX) yields two monobranched isomers, 2-methylpentane (2MP) and 3-methylpentane (3MP), and two dibranched isomers, 2,2-dimethylbutane (22DMB) and 2,3-dimethylbutane (23DMB). These $C_{6}$ isomers have octane ratings of $21,80,83,93$ and 101 , respectively. The isomerization is performed using a bi-functional catalyst, having a (de)hydrogenation function and an acid function. Nowadays the most commonly used catalysts are platinum loaded mordenite (Pt/H-MOR) and platinum on chlorinated alumina (Pt/ $\mathrm{Al}_{2} \mathrm{O}_{3}-\mathrm{Cl}$ ) [1]. Separation of the non-converted linear molecules is carried out using adsorbing beds of zeolite 5A. Nevertheless,

\footnotetext{
* Corresponding authors. Address: Escola Superior de Tecnologia e Gestão, Instituto Politécnico de Bragança, Apartado 1134, 5301-857 Bragança, Portugal. Tel.: +351 27330 3191; fax: +351273313051 (P.S. Bárcia), tel.: +31 (0) 15 2789820; fax: +31 (0) 152785006 (J. Gascon).

E-mail addresses: patrick.barcia@ipb.pt (P.S. Bárcia), j.gascon@tudelft.nl (J. Gascon).
}

approximately one third of the resulting isomerate consists of low octane number $(\mathrm{ON})$ linear and monobranched alkanes. The world conjuncture in the refining markets is stressing the need for alternative solutions which can improve the ON quality of the gasoline fulfilling at the same time the environmental standards imposed.

Interest in zeolite membranes has been growing rapidly in both the scientific and industrial field due to their capability to separate compounds in continuous operation. In this work, different synthesis methods for manufacturing zeolite Beta membranes have been explored and their performance in the vapour phase separation of hexane isomer mixtures has been studied. This work presents the mixture separation of four hexane isomers ( $n \mathrm{HEX}, 3 \mathrm{MP}, 23 \mathrm{DMB}$ and 22DMB) through pervaporation using zeolitic membranes.

In the literature, most studies concerning the adsorption and separation of branched $\mathrm{C}_{6}$ isomers focus on the use of MFI (Silicalite-1 or ZSM-5) as adsorbent [2-8]. Molecular simulation studies for MFI suggest theoretically that the selectivities mono-/dibranched alkanes increases at high coverage due to configurational entropy effects $[3,4]$. In preceding works, experimental measurements [5] and subsequent modelling of the transport of hexane isomers through ZSM-5 membranes [6], showed selectivities $n \mathrm{HEX} / 3 \mathrm{MP}$ and $n \mathrm{HEX} / 22 \mathrm{DMB}$ up to 100 and 1000 , respectively, 


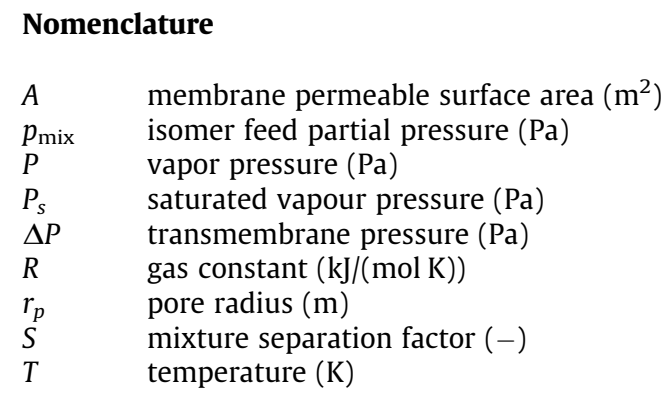

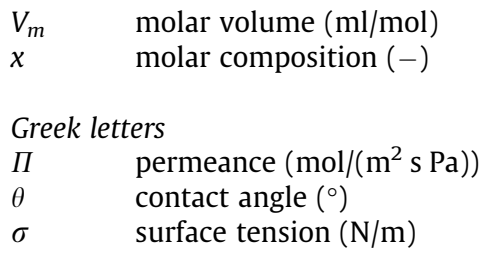

based on permeation rates of the hydrocarbons across the membrane. However, Gora and Jansen [7] found much lower selectivity, only 24 for the vapour permeation of a mixture $n \mathrm{HEX} / 2 \mathrm{MP}$ with a molar ratio of 80:20 (22 mol\% in Helium) at $393 \mathrm{~K}$ with a Silicalite$1 / \mathrm{TiO}_{2} /$ stainless steel tubular membrane. Similar $n \mathrm{HEX} / 2 \mathrm{MP}$ and $n$ HEX/3MP selectivities, 22 and 24, respectively, were reported by Funke et al. [8] for the permeation of equimolar mixtures through ZSM-5 membranes (2-10 $\mu$ m thickness) on $\gamma$-alumina tubular support at $363 \mathrm{~K}$. Interestingly, in the same work separation of $3 \mathrm{MP} / 22 \mathrm{DMB}$ mixtures was not possible at the same conditions.

Zeolite Beta possesses a three-dimensional 12-ring pore structure consisting of perpendicular straight channels $6.6 \times 6.7 \AA$ which interconnections create narrow helicoidal channels of effective pore diameter $5.6 \times 5.6 \AA$ A . In recent adsorption equilibrium studies performed by our group, Bárcia et al. [9-11] indicated that zeolite Beta can be a useful adsorbent for the vapour phase separation of $C_{6}$ isomer mixtures at low partial pressure by fixed bed technique. These authors suggest that the selective adsorption of linear and monobranched hexanes in zeolite Beta could be explained by the shape selective behaviour of the narrow channels which block the access of the bulkier dibranched hexanes. Recently, Maloncy et al. [12] used two different methods to synthesize zeolite Beta (BEA) membranes by seeding and secondary growth technique on $\mathrm{TiO}_{2}$ coated stainless steel disk supports. These membranes were afterwards used in pervaporation of equimolar mixtures of 2MP and 22DMB at $303 \mathrm{~K}$ showing selectivities of 1.5 in favour of the monobranched isomer. In situ crystallization was used by Tuan et al. [13], resulting in highly crystalline zeolite Beta membranes which were tested for the separation of organic compounds. The same crystallization technique was used by Torres et al. $[14,15]$ on porous $\mathrm{Al}_{2} \mathrm{O}_{3}$ supports using a three-step method with different gel precursor dilutions resulting in a homogenous zeolite Beta film.

In this study, various synthesis procedures of BEA membranes were evaluated for their applicability in the separation of hexane isomers. BEA membranes were prepared by secondary growth method combining different seeding techniques, seeding materials and posterior hydrothermal synthesis conditions reported elsewhere $[12,13,15,16]$. These membranes were characterized and their potential for the separation of branched hexane isomers was studied. Their performances are compared with the state of the art membrane processes.

\section{Experimental}

\subsection{Preparation of $\alpha$-alumina supported zeolite Beta membranes}

Zeolite Beta membranes were grown on the inner surface of asymmetric tubular $\alpha-\mathrm{Al}_{2} \mathrm{O}_{3}$ supports (Inocermic $\mathrm{GmbH}$, Germany) with a $D_{\mathrm{i} / \mathrm{o}}$ of $7 / 10 \mathrm{~mm}$, and a length of $80 \mathrm{~mm}$ having a top layer on the inner surface containing pores of $200 \mathrm{~nm}$. The effective length was about $54 \mathrm{~mm}$ because a glazing of $13 \mathrm{~mm}$ was applied at both ends. After coating on each support end with the glazing (IN 1001 Clear, Envision Glaze, Duncan) the supports were heated at $1273 \mathrm{~K}$ for $15 \mathrm{~min}$ at a heating rate of $1-3 \mathrm{~K} \mathrm{~min}^{-1}$. During the membrane synthesis, the outer side of the tube was covered with Teflon tape to avoid crystallization on this side.

The zeolite Beta membranes were prepared by a secondary growth method combining three different types of seeding techniques and materials at three different crystallization conditions (see Table 1).

The first seeding method is based on a pressure gradient technique: vacuum was applied inside a flask containing plugged supports previously filled with a suspension $(15 \mathrm{ml})$ of commercial Beta crystals (crystal size: $0.1-4 \mu \mathrm{m}$; $\mathrm{Si} / \mathrm{Al}=12.5$ ) in the $\mathrm{H}$-form $(10 \mathrm{~g} / \mathrm{l})$. The commercial Beta crystals were supplied by ZEOCHEM AG under the reference ZEOcat ${ }^{\circledR} \mathrm{PB} / \mathrm{H}$. The water is then filtered through the vertically placed support tube, where the seed crystals are deposited on its inner surface. The process was repeated twice while inverting the orientation of the support to achieve a homogeneous distribution of the seeds.

The same pressure gradient technique was applied in the seeding method 2 using a colloidal suspension of Na-BEA prepared as described elsewhere [12]. Dip-coating was used in method 3 to fix nanocrystalline zeolite Beta on the internal surface of the supports [16]. The colloidal suspensions used in methods 2 and 3 were prepared by hydrothermal synthesis in Teflon lined stainless steel autoclaves. Both gel phase compositions and hydrothermal synthesis conditions are summarized in Table 1 . The seeded supports were then hydrothermally treated twice using three different mixtures containing tetraethylammonium hydroxide (TEAOH) as a structure directing agent (SDA). The crystallization methods used in this work are summarized in Table 1 . After each crystallization step, the membranes were brushed, thoroughly washed with distilled water, and dried in air at $373 \mathrm{~K}$ for $12 \mathrm{~h}$.

Finally the template was removed from the membranes by calcination in air at $753 \mathrm{~K}$ for $8 \mathrm{~h}$ at a heating rate of $0.3 \mathrm{~K} \mathrm{~min}^{-1}$.

\subsection{Static characterization of membranes and materials}

After hydrothermal synthesis, the powders collected from the bottom of the autoclaves were analysed by X-ray diffraction (XRD) using a Bruker-AXS D5005 with $\mathrm{Cu} \mathrm{K \alpha}$ radiation. The surfaces and cross sections of the supports were examined by scanning electron microscopy (SEM) on a Phillips XL20 (15 kV) microscope to determine the morphology, homogeneity, adhesion and thickness of the zeolite layer as well as the crystal sizes.

\subsection{Dynamic characterization of supported membranes}

The quality of the membranes was evaluated after each synthesis as well as after the calcination by measuring the permeance of pure $\mathrm{N}_{2}$ at room temperature. In a membrane module with both 
Table 1

$\mathrm{N}_{2}$ permeance of the zeolite Beta membranes after second synthesis and after calcination. Transmembrane pressure difference of $200 \mathrm{kPa}$. Room temperature. Si/Al ratio calculated from the composition of the synthesis mixture.

\begin{tabular}{|c|c|c|c|c|}
\hline \multirow[t]{2}{*}{$\mathrm{N}_{2}$ permeance, $\Pi\left(\mathrm{mol} /\left(\mathrm{m}^{2} \mathrm{~s} \mathrm{~Pa}\right)\right)$} & & \multicolumn{3}{|l|}{ Secondary growth } \\
\hline & & $\begin{array}{l}\text { Synthesis } \mathrm{A}[15]^{\mathrm{e}} \\
\mathrm{Si} / \mathrm{Al}=45 \\
\text { Synthesis conditions: } \\
443 \mathrm{~K} / 3 \text { days } \\
\text { Two syntheses }\end{array}$ & $\begin{array}{l}\text { Synthesis B [12 }]^{\mathrm{f}} \\
\mathrm{Si} / \mathrm{Al}=192 \\
\text { Synthesis conditions: } 423 \mathrm{~K} / 4 \\
\text { days } \\
\text { Two syntheses }\end{array}$ & $\begin{array}{l}\text { Synthesis } \mathrm{C}[13]^{\mathrm{g}} \\
\mathrm{Si} / \mathrm{Al}=12 \\
\text { Synthesis conditions: } 393 \mathrm{~K} / 6 \\
\text { days } \\
\text { Two syntheses }\end{array}$ \\
\hline $\begin{array}{l}\text { Seeding } 1^{\mathrm{b}} \\
\quad \mathrm{Si} / \mathrm{Al}=12.5 \\
\text { Seeding by vacuum }\end{array}$ & $\begin{array}{l}\text { After second synth. } \\
\text { Calcined }\end{array}$ & $\begin{array}{l}\text { MB_1: } \Pi=1.4 \times 10^{-9} \\
\text { MB_2: } \Pi \Rightarrow \text { gas tight } \\
\text { MB_1 } \\
\text { MB_2: } \Pi=7.7 \times 10^{-7}\end{array}$ & $\begin{array}{l}\text { MB_7: } \Pi=1.6 \times 10^{-9} \\
\text { MB_8: } \Pi=1.0 \times 10^{-9} \\
\text { MB_7 } \\
\text { MB_8: } \Pi=1.5 \times 10^{-6}\end{array}$ & $\begin{array}{l}\text { MB_13: } \Pi=2.0 \times 10^{-7} \\
\text { MB_14: } \Pi=3.4 \times 10^{-7} \\
\text { MB_13: } \Pi=1.8 \times 10^{-6} \\
\text { MB_14 }\end{array}$ \\
\hline $\begin{array}{l}\text { Seeding } 2[12]^{\mathrm{c}} \\
\mathrm{Si} / \mathrm{Al}=25 \\
\text { Synthesis conditions: } 423 \mathrm{~K} / 40 \mathrm{~h}\end{array}$ & After second synth. & $\begin{array}{l}\text { MB_3: } \Pi=3.0 \times 10^{-10} \\
\text { MB_4: } \Pi \Rightarrow \text { gas tight }\end{array}$ & $\begin{array}{l}\text { MB_9: } \Pi=2.7 \times 10^{-9} \\
\text { MB_10: } \Pi=8.6 \times 10^{-8}\end{array}$ & $\begin{array}{l}\text { MB_15: } \Pi=3.6 \times 10^{-10} \\
\text { MB_16: } \Pi=3.2 \times 10^{-9}\end{array}$ \\
\hline Seeding by vacuum & Calcined & $\begin{array}{l}\text { MB_3 } \\
\text { MB_4: } \Pi=6.3 \times 10^{-7}\end{array}$ & $\begin{array}{l}\text { MB_9: } \Pi=8.8 \times 10^{-7} \\
\text { MB_10 }\end{array}$ & $\begin{array}{l}\text { MB_15: } \Pi=6.0 \times 10^{-7} \\
\text { MB_16 }\end{array}$ \\
\hline $\begin{array}{l}\text { Seeding } 3[16]^{\mathrm{d}} \\
\quad \mathrm{Si} / \mathrm{Al}=100 \\
\text { Synthesis conditions: } 413 \mathrm{~K} / 4 \text { days } / 60 \mathrm{rpm}\end{array}$ & After second synth. & $\begin{array}{l}\text { MB_5: } \Pi \Rightarrow \text { gas tight } \\
\text { MB_6: } \Pi \Rightarrow \text { gas tight }\end{array}$ & $\begin{array}{l}\text { MB_11: } \Pi=4.6 \times 10^{-8} \\
\text { MB_12: } \Pi=1.7 \times 10^{-7}\end{array}$ & $\begin{array}{l}\text { MB_17: } \Pi \Rightarrow \text { gas tight } \\
\text { MB_18: } \Pi=3.8 \times 10^{-10}\end{array}$ \\
\hline Seeding by dip-coating & Calcined & $\begin{array}{l}\text { MB_5: } \Pi=4.4 \times 10^{-7} \\
\text { MB_6: } \Pi=4.9 \times 10^{-7}\end{array}$ & $\begin{array}{l}\text { MB_11: } \Pi=1.4 \times 10^{-6} \\
\text { MB_12 }\end{array}$ & $\begin{array}{l}\text { MB_17: } \Pi=7.9 \times 10^{-7} \\
\text { MB_18 }\end{array}$ \\
\hline
\end{tabular}

${ }^{a}$ Non-calcined membranes: broken for SEM analysis after second synthesis.

b Commercial Beta crystals (H-form) supplied by ZEOCHEM in distilled water ( $10 \mathrm{~g} / \mathrm{l})$; gel composition.

c $\mathrm{SiO}_{2}$ : $0.02 \mathrm{Al}_{2} \mathrm{O}_{3}: 0.25$ (TEA) $)_{2} \mathrm{O}: 15 \mathrm{H}_{2} \mathrm{O}: 0.0394 \mathrm{Na}_{2} \mathrm{O}: 0.02 \mathrm{~K}_{2} \mathrm{O}: 0.058 \mathrm{HCl}$.

d $200 \mathrm{SiO}_{2}: \mathrm{Al}_{2} \mathrm{O}_{3}: 53$ (TEA) $2 \mathrm{O}: 3000 \mathrm{H}_{2} \mathrm{O}$.

e $90 \mathrm{SiO}_{2}: \mathrm{Al}_{2} \mathrm{O}_{3}: 22.5$ (TEA) ${ }_{2} \mathrm{O}: 1.62 \mathrm{~K}_{2} \mathrm{O}: 3.20 \mathrm{Na}_{2} \mathrm{O}: 4320 \mathrm{H}_{2} \mathrm{O}$.

f $\mathrm{SiO}_{2}$ : $0.0026 \mathrm{Al}_{2} \mathrm{O}_{3}: 0.269$ (TEA) $)_{2} \mathrm{O}: 15.5 \mathrm{H}_{2} \mathrm{O}$.

g TEOS: $0.0429 \mathrm{Na}_{2} \mathrm{Al}_{2} \mathrm{O}_{4}$ : 0.313 (TEA) $)_{2} \mathrm{O}: 10.393 \mathrm{H}_{2} \mathrm{O}$.

retentate outlet and permeate inlet closed, the inlet flowrate of $\mathrm{N}_{2}$ in the retentate is varied until the pressure stabilizes (permeate side at atmospheric pressure). The flux of $\mathrm{N}_{2}$ through the membrane is then measured at the steady-state. The permeance $\Pi$ was calculated based on the measured flow and on the membrane area, considering a transmembrane pressure difference of $200 \mathrm{kPa}$.

The existence of defects in the Beta membranes was examined by pervaporation of 1,3,5-triisopropylbenzene (TIPB) in ethanol (10 wt\% of TIPB) at room temperature [17] and by nanopermporometry. The setup presented in Fig. 1 was used for the pervaporation test by actuating valve $V_{2}$ and closing valves $V_{5}$ and $V_{6}$. The permeate side was kept under vacuum $\left(\Delta P_{\max }=985 \mathrm{~Pa}\right)$. A cold trap cooled with liquid nitrogen was used to continuously collect the permeate vapour which was later analysed by chromatography. The mixture separation factor, $S$, is given by the following expression:

$$
S_{12}=\frac{x_{1} / x_{2 \text { Permeate }}}{x_{1} / x_{2 \text { Feed }}}
$$

here, $x$ is the molar fraction, with component 1 the more permeable molecule.

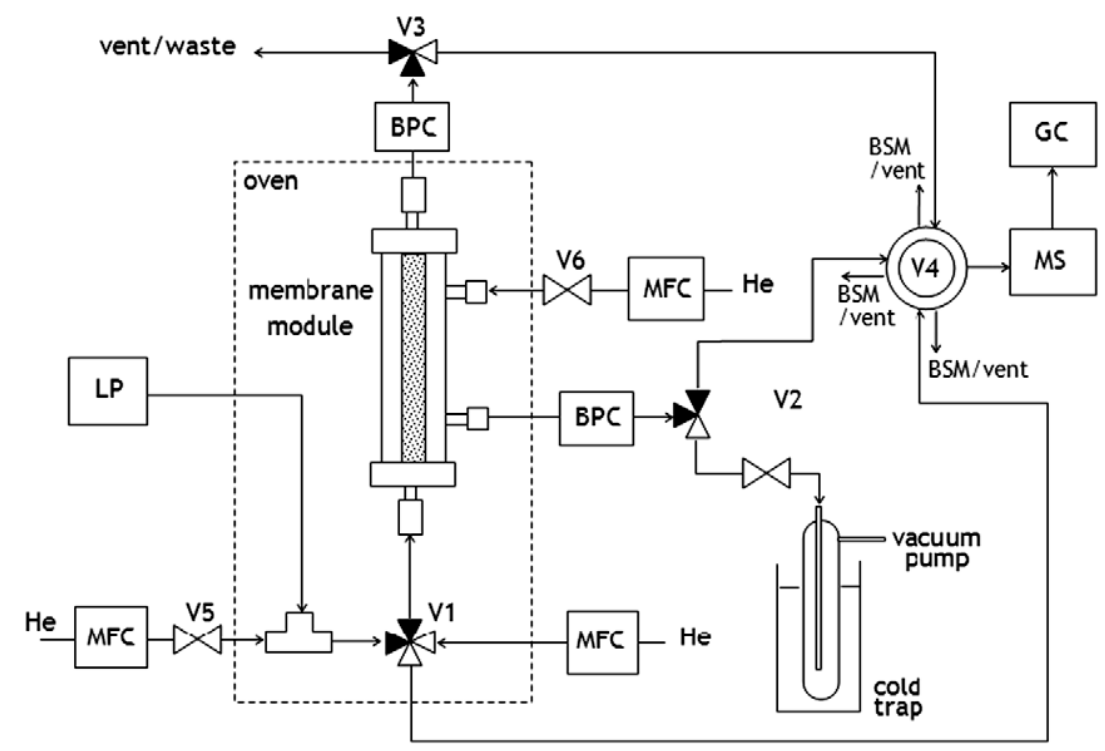

Fig. 1. Schematic representation of the experimental setup used for vapour permeation and pervaporation test: BPC - back pressure controller; BSM - bubble soap meter, GC - gas chromatograph; LP - liquid pump (HPLC pump or syringe pump); MFC - gas mass flow controller; MS - mass spectrometer; V1 - 4-way crossover valve; V2 and V3 - 3way valve; V4 - multiposition valve; V5 and V6 - open/close valve. 


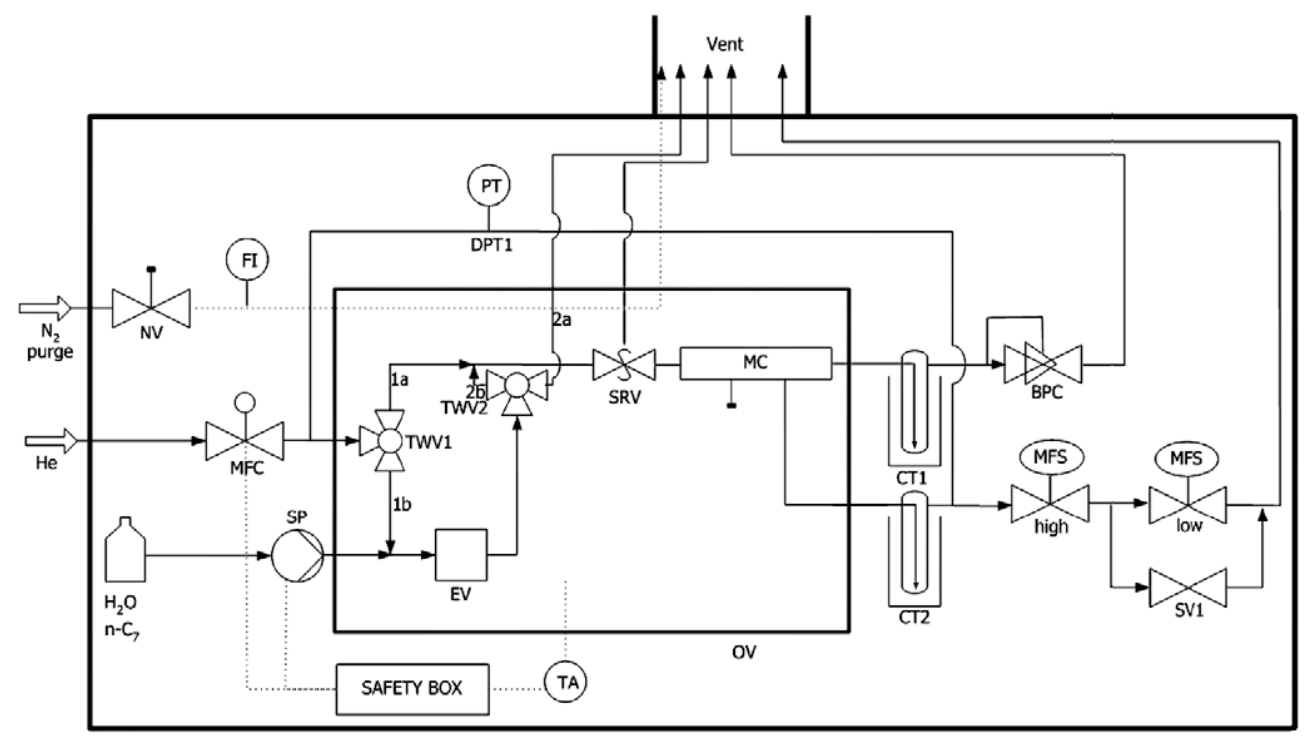

Fig. 2. Schematic representation of the nano-permporometry setup: BPC - back pressure controller; CT - cold trap; DPT - differential pressure transmitter; EV - evaporation vessel; FI - flow indicator; MC - membrane cell; MFC - mass flow controller; MFS - mass flow system; NV - needle valve; OV - oven; SP - syringe pump; SV - shutoff valve; SRV - safety relief valve; TA - temperature alarm; TWV - three way valve.

Nano-permporometry experiments were performed in a homemade setup (Fig. 2) using $n$-heptane as condensable. First the permeation of dry Helium was measured at the studied temperature $(323 \mathrm{~K})$, then the vapour pressure of $n$-heptane was increased gradually in a stepwise manner to a specific partial pressure while measuring the He permeate flow. The pressure difference between permeate and retentate was fixed at $25 \mathrm{kPa}$. For the measurement of the pore size distribution of defects, the Kelvin equation was used:

$R T \ln \left(\frac{P}{P_{s}}\right)=-2 V_{m} \frac{\sigma \cos \theta}{r_{p}}$

where $V_{m}, \sigma, \theta$ and $r_{p}$ are the molar volume, surface tension, contact angle and pore radius, respectively. $R$ is the universal gas constant and $T$ is the temperature. Capillary condensation occurs in smaller pores at vapor pressure $P$ lower than the saturated vapor pressure $P_{s}$. Since the condensed vapour can be assumed to block the permeation of the non-condensable gas, it is possible to estimate the pore size distribution by measuring the permeation rate as a function of the vapour pressure of the condensable gas in the feed stream $[18,19]$.

The vapour separation tests were performed in the setup schematized in Fig. 1. The experiments were carried out at $373 \mathrm{~K}$ and atmospheric pressure on both sides of the membrane. The feed consisted on an equimolar mixture of 22DMB, 23DMB, 3MP and $n$ HEX. Both He-carrier gas flow rate and He sweep flow rate were set to $50 \mathrm{ml} / \mathrm{min}$. A molar feed ratio of $99 / 1 \mathrm{He} / \mathrm{C}_{6}$, was used. The evolution of hydrocarbon flow in both retentate and permeate streams was continuously measured by means of a mass spectrometer (Ledamass Quadrupole Mass Analyser). A gas chromatograph (Chrompack CP-9001) equipped with a RTX-1 column (Restek, $60 \mathrm{~m} \times 0.32 \mathrm{~mm} \mathrm{ID} \times 1.5 \mu \mathrm{m}$ ) was used to accurately evaluate the composition of the hydrocarbon mixture in the permeate stream. The separation factor, $S$, is given by Eq. (1).

\section{Results and discussion}

Fig. 3 shows the XRD patterns of every powder sample collected from the bottom of the autoclave after the hydrothermal synthesis. The diffraction peaks observed at $2 \theta=7.7^{\circ}$ and $2 \theta=22.5^{\circ}$ for all samples are in agreement with the more intense peaks of the reference commercial zeolite Beta crystals ( $\mathrm{H}$-form) provided by SüdChemie $(\mathrm{Si} / \mathrm{Al}=75)$. It is noted that the reference commercial Beta

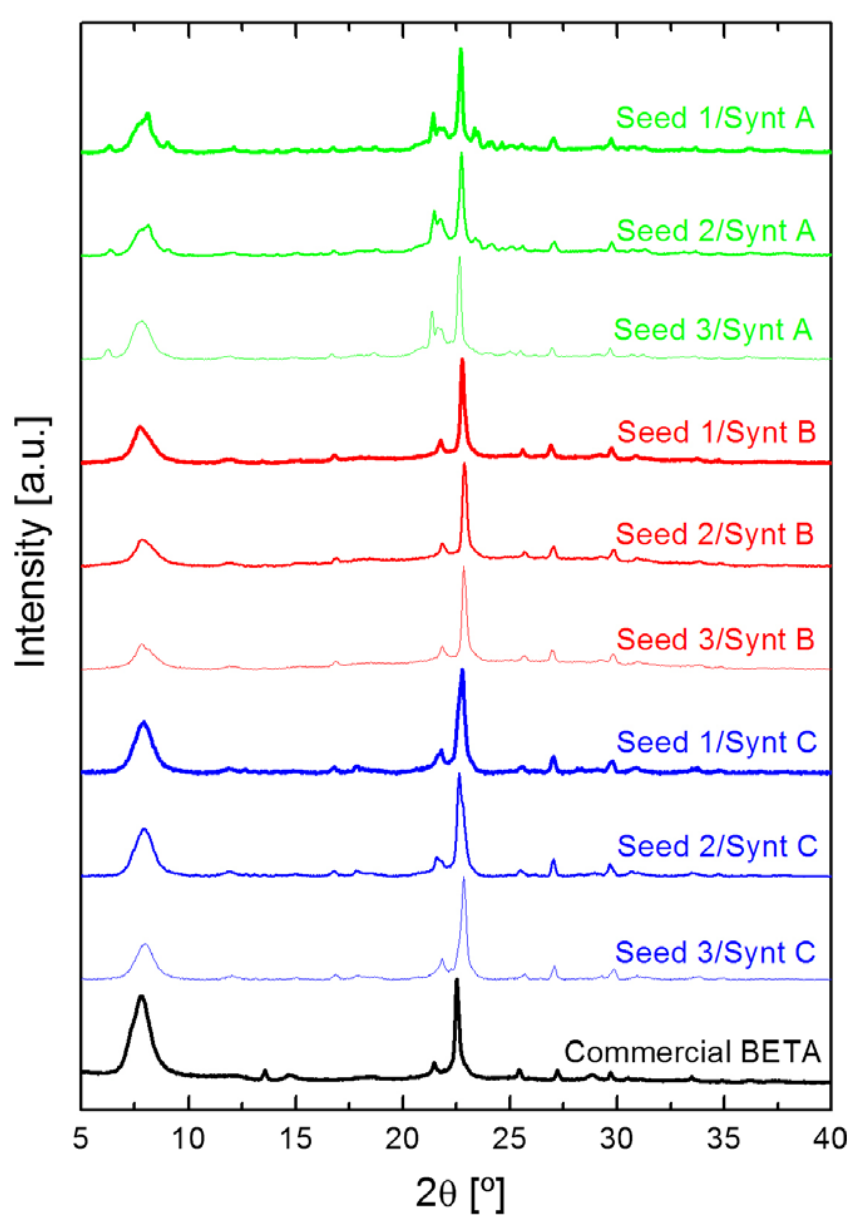

Fig. 3. XRD patterns of uncalcined powder collected from the Beta membranes synthesis compared with the (calcined) reference commercial zeolite Beta. 
sample and the commercial sample used for the seeding method 1 do not originate from the same manufacturer. The commercial reference Beta sample has been studied in detail in preceding works by our group for the separation of hexane isomers in fixed bed [9-11]. The slight shift of all samples relatively to the reference sample is due to the fact the latter was a calcined sample. Despite the different synthesis conditions, the intensity of the characteristic reflections observed for all the samples does not change significantly, suggesting a similar degree of crystallinity. The broad reflection at $2 \theta=7.7^{\circ}$ indicates all membranes are an intergrowth mixture of polymorph A and B of the Beta zeolite. However, the additional features at $2 \theta=9.2^{\circ}$ for the powder collected from synthesis method A (Seed 1 and 2) could indicate that the presence of polymorph A correspond at least to $80 \%$ of the crystalline structure [20].

Single gas permeation measurements using $\mathrm{N}_{2}$ were carried out after each synthesis, at room temperature, on every membrane to verify the quality of the zeolite films. The addition of a second zeolite Beta layer onto the supports decreased the $\mathrm{N}_{2}$ permeance of at least $80 \%$, except for membranes MB_9, MB_10 and MB_12, pre-
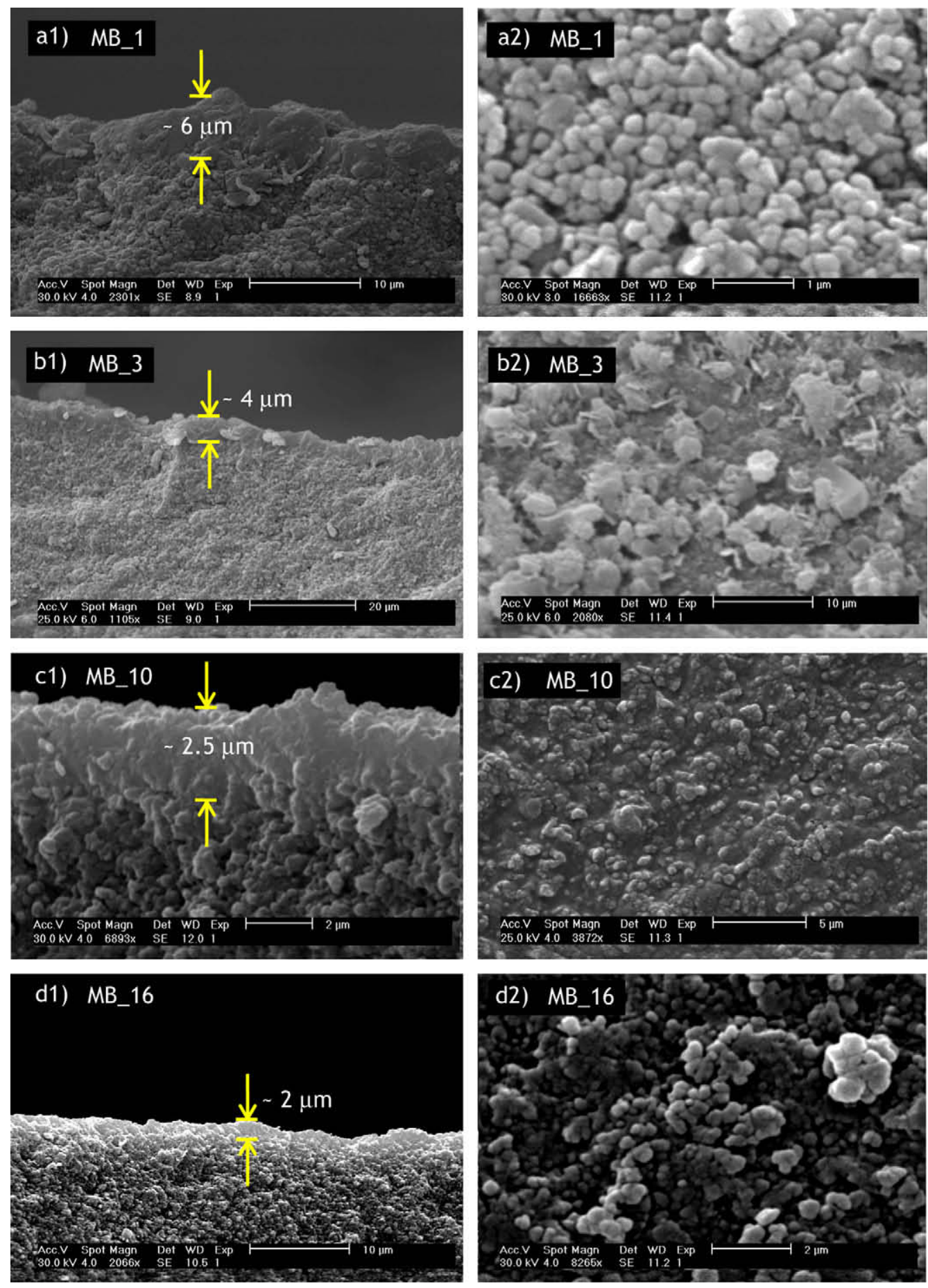

Fig. 4. SEM micrographs of different non-calcined Beta membranes. (a1-a2) Membrane MB_1; (b1-b2) membrane MB_3; (c1-c2) membrane MB_10; (d1-d2) membrane MB_16. Cross section view (left side) and top view (right side). 
pared by synthesis method $\mathrm{B}$. The higher concentration of the solution used in this synthesis has probably contributed to homogenous nucleation (in solution/liquid phase) causing at the same time the partial dissolution of the zeolite film formed during the first synthesis. Results in Table 1 show that leak tight Beta membranes can be obtained after two hydrothermal treatments using the synthesis method A. The combination of seeding method 3 with synthesis method A seems to be the most effective procedure to obtain good quality membranes, although the type of seeding hardly affected the quality of the membranes. After calcination, the $\mathrm{N}_{2}$ permeation indicates values varying from $10^{-7}$ to $10^{-6} \mathrm{~mol} /\left(\mathrm{m}^{2} \mathrm{~s} \mathrm{~Pa}\right)$, much lower than those of the $\alpha-\mathrm{Al}_{2} \mathrm{O}_{3}$ support $\left(\sim 10^{-5} \mathrm{~mol} /\left(\mathrm{m}^{2} \mathrm{~s} \mathrm{~Pa}\right)\right)$. The $\mathrm{N}_{2}$ permeance measured for the membranes MB_5 and MB_6 is similar to that obtained by Flanders et al. through an alumina supported H-ZSM-5 membrane [5].

Noteworthy is the influence of the use of seeds in the preparation of Beta membranes by method $C$, since only two syntheses were required to obtain permeances of the same order of magnitude $\left(10^{-7} \mathrm{~mol} /\left(\mathrm{m}^{2} \mathrm{~s} \mathrm{~Pa}\right)\right)$ as obtained by Tuan et al. after five syntheses of 6 days each [13]. Such results clearly show that seeding could account for the compactness of the Beta films.

Fig. 4 shows the cross sectional view and top view micrographs of four zeolite Beta membranes. The cross sectional views clearly show the zeolite layer on the top of the alumina layer. The zeolite and the alumina layers are well intergrown for all the membranes. SEM images suggest a zeolite layer thickness of about 4-6 $\mu \mathrm{m}$ for the membranes synthesized through method A (Fig. 4a1 and b1), while methods $B$ and $C$ produce thinner layers of about 2.0$2.5 \mu \mathrm{m}$ (Fig. 4c1 and d1). Both thickness and morphology of mem-

Table 2

Pervaporation experiments at room temperature with a $10 \mathrm{wt} \%$ TIPB mixture in ethanol.

\begin{tabular}{lll}
\hline Membrane & $\begin{array}{l}\text { Permeate composition } \\
\text { (wt\% of TIPB) }\end{array}$ & $\begin{array}{l}\text { Ethanol/TIPB } \\
\text { separation factor }\end{array}$ \\
\hline MB_2 & 0.7 & 16 \\
MB_4 & 0.9 & 12 \\
MB_5 & 0.3 & 32 \\
MB_6 & 0.4 & 30 \\
MB_9 & 0.3 & 32 \\
MB_15 & 0.8 & 14 \\
\hline
\end{tabular}

brane $\mathrm{MB}_{-} 10$ were in agreement with the results of Maloncy et al. [12] using the same synthesis conditions on $\mathrm{TiO}_{2}$ coated stainless steel disk supports.

The top views in Fig. 4 show that the surface of the membranes has a continuous layer of well intergrown crystals with a non-uniform size distribution ranging from 0.2 to $0.7 \mu \mathrm{m}$ in diameter, except for MB_3, in which the size of the crystals seems to be slightly bigger (around $2 \mu \mathrm{m}$ ). The polycrystalline network of membrane MB_10 appears to be better plugged, nevertheless this type of surface is more susceptible to form cracks during the calcination procedure due to differences in thermal expansion between the zeolite and the support.

In order to evaluate the compactness of the most promising zeolite Beta membranes, pervaporation experiments of a mixture containing $10 \mathrm{wt} \%$ of TIPB diluted in ethanol were carried out at room temperature for $30 \mathrm{~min}$. The results of the pervaporation experiments are given in Table 2. Low concentrations of TIPB were detected in the permeate for all the membrane tested. Since the kinetic diameter of TIPB $(8.5 \AA)$ is greater than the pore size of zeolite Beta $(7.6 \times 6.4 \AA)$, these results indicate that the membranes contain some larger, non-zeolitic pathways. The most selective membranes MB_5, MB_6 and MB_9 exhibited a separation factor ethanol/TIPB $\geqslant 30$.

Quantification of the amount of defects in the zeolite membranes was determined by permporometry. In Fig. 5 , the residual Helium permeance was plotted as a function of the Kelvin diameter, which can be directly calculated from Eq. (2). The permporometry results are in fair agreement with the pervaporation of TIPB results. MB_15 and MB_4 exhibited in both cases the worst performance, a low ethanol/TIPB separation factor together with a high contribution of defects. Among the other membranes, MB_5 and MB_6 present less than a $5 \%$ of defect contribution to the total flux. Membrane MB_4 showed interestingly a relatively high contribution ( $8 \%)$ of small defects $(<3 \mathrm{~nm})$ but a negligible contribution of large defects. This is attributed to permeation along grain boundaries. All membranes show this phenomenon to a more or lesser extent.

The separation performance of the characterized membranes was tested in the separation of quaternary equimolar mixtures of $n$ HEX, 3MP, 23DMB and 22DMB through vapour permeation at $373 \mathrm{~K}$. The mass spectrometer analysis indicated that steady-state was attained in less than $1 \mathrm{~h}$ for all the membranes tested, being

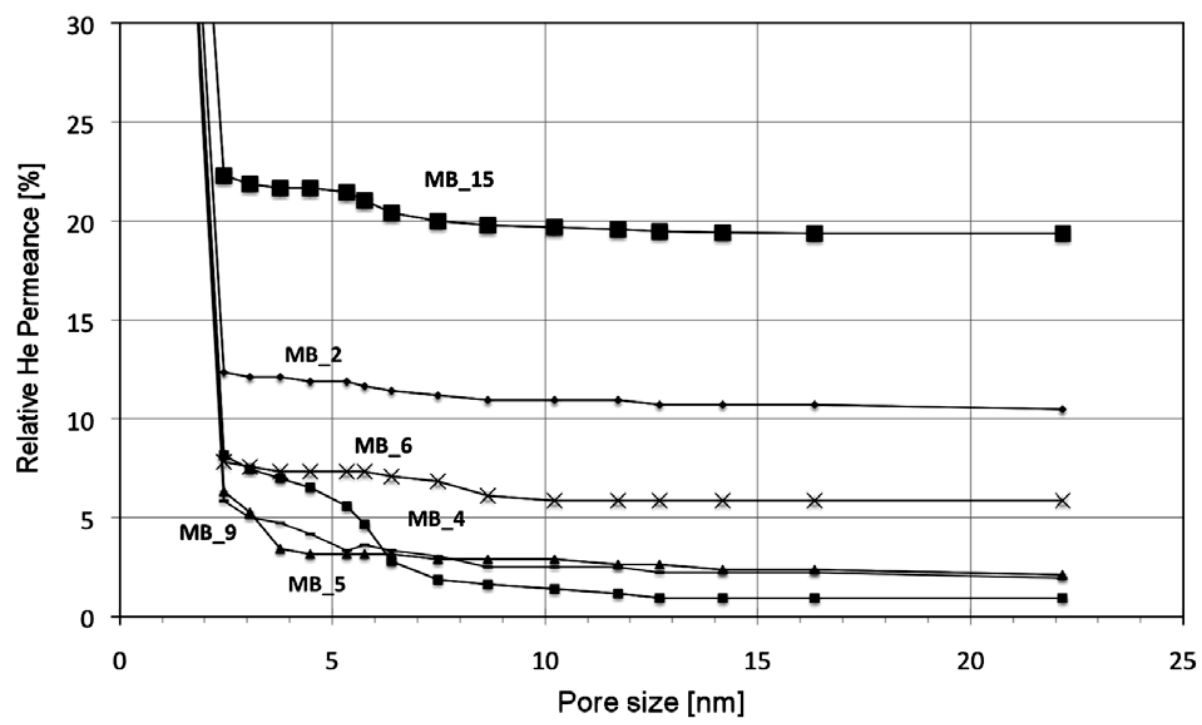

Fig. 5. Permporometry characterization of the different BEA membranes showing the residual Helium permeance as a measure of the defect concentration. Pore diameters were calculated according to Eq. (2) considering $\cos (\theta)=1 . T=323 \mathrm{~K}, \Delta P=25 \mathrm{kPa}$. 
the steady-state permeate fluxes compared in Fig. 6 . The permeate flux decreases as the degree of branching increases following the order: $n \mathrm{HEX}$ " $3 \mathrm{MP}>23 \mathrm{DMB}>22 \mathrm{DMB}$. Such result suggests that permeation hierarchy can be dictated by the mobility as well as the sorption affinity of the molecules. Assuming a similar degree of crystallinity for all the membranes synthesized the main factors which may affect their separation performances include: open grain boundaries (which can act as non-zeolitic pores); cracks resulting from detemplation or thermal expansion; Si/Al ratio; film thickness and preferential crystal orientation [21]. All these factors may account for the features shown in Fig. 6, but the differences of the fluxes are not significant enough to allow distinction between the influence of any of the parameters previously mentioned.

Approximately $40 \%$ of the feed flow crosses the membranes, except for MB_2 and MB_15 where the permeation fraction represents $24 \%$ and $49 \%$ of the feed flow, respectively (see Table 3 ). Such differences in hydrocarbon fluxes are in agreement with the film thickness of their peer membrane MB_1 and MB_16 which are 6 and $2 \mu \mathrm{m}$ thick, respectively (see Fig. 4).

At $373 \mathrm{~K}$ the best membranes in terms of mono-/dibranched isomer separation are MB_4 and MB_5 (Table 3), with MB_5 having the highest selectivity with $S_{3 \mathrm{MP} / 22 \mathrm{DMB}}=1.4$. A comparable value was obtained by Maloncy et al. for pervaporation of a binary mixture $2 \mathrm{MP} / 22 \mathrm{DMB}$ at $303 \mathrm{~K}$ [12]. Also the values for the permeances of the different isomers are of the same order as reported by Mal-

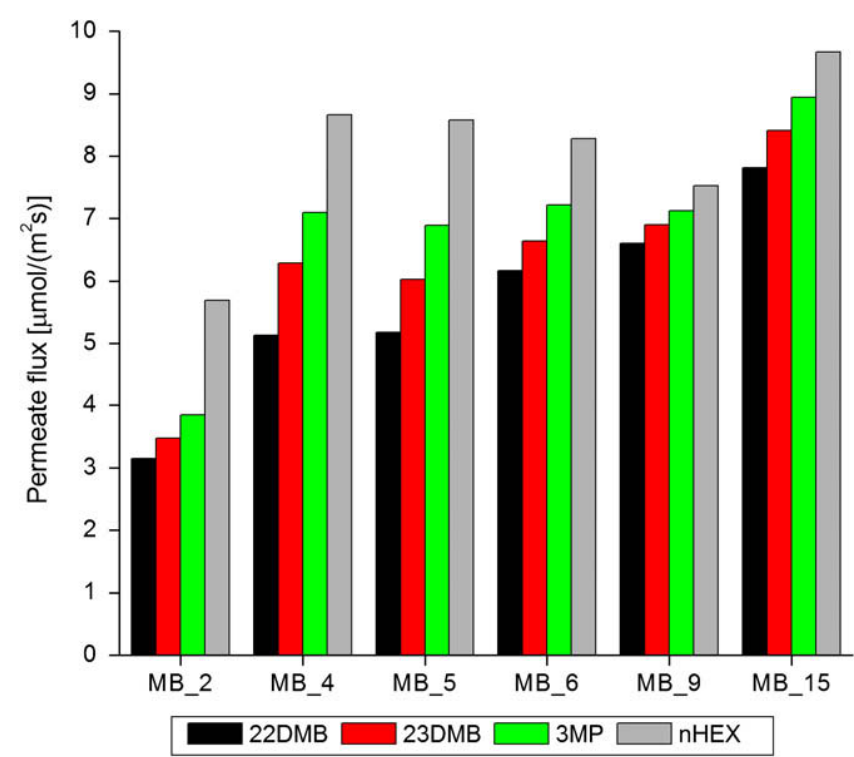

Fig. 6. Permeate fluxes of 22DMB, 23DMB, 3MP and $n \mathrm{HEX}$ equimolar mixture at $T=373 \mathrm{~K}$ and $p_{\text {mix }}=1 \mathrm{kPa}$ through $\alpha-\mathrm{Al}_{2} \mathrm{O}_{3}$ supported zeolite Beta membranes. oncy et al. [12] for BEA membranes of similar thickness. However, comparisons should be made with caution since in the present study a more complex quaternary system is considered. Funke et al. [8] obtained no selectivity 3MP/22DMB when using a Silicalite-1 membrane, suggesting a better performance of Beta for the branched hexanes separation. Surprisingly, membrane MB_2 exhibits a high separation factor for $n$ HEX (for instance, $S_{n \text { HEX/ }}$ $22 \mathrm{DMB}=1.81$ ), while it shows the expected low selectivity for separation of the mono- from dibranched isomers. The selectivity $n \mathrm{HEX} /$ dibranched isomers reported in the literature for MFI membranes $[5,7,8]$ are significantly higher than those measured in this work for BEA membranes. However it should be emphasized that the separation mono-/dibranched C6 isomers is the key factor for improving the octane quality of the gasoline.

Clearly, the narrower pores of MFI perform better in the separation of the linear from branched isomers, whereas the wider BEA pores discriminate between monobranched and dibranched isomers. In principle, interesting results could be obtained combining the performances of both structures in such a way that linear/ branched and mono-/dibranched separations could be achieved in two subsequent steps.

It has been reported that adsorption of $n$ HEX in MFI may induce crystal swelling [22]. Although XRD and optical microscopy studies show that crystal expansion is less than $0.5 \%$, such expansion can essentially seal $2 \mathrm{~nm}$ membranes [22]. It has been also suggested that the degree of sealing micro-defects depends on both arrangement/orientation of the crystals and thickness of the membrane [22]. A combination of these effects could account for the peculiar separation performance of membrane MB_4.

Fig. 7 shows the molar composition of the retentate stream for vapour permeation of an equimolar quaternary mixture $n \mathrm{HEX} /$ $3 \mathrm{MP} / 23 \mathrm{DMB} / 22 \mathrm{DMB}$ through the zeolite membranes at $373 \mathrm{~K}$. For all the membranes examined, the concentration of the dibranched hexane isomers was increased, while the amount of $n$ HEX was significantly reduced. The figure also shows the octane number (ON) gain in the retentate, $\Delta \mathrm{ON}$, which corresponds to the difference, $\mathrm{ON}_{\text {Retentate }}-\mathrm{ON}_{\text {Feed }}$. Considering an average value of $74.4 \mathrm{ON}$ in the hydrocarbon feed, then, the $\mathrm{ON}$ of the mixture can be boosted up to 4 points with the membrane produced by the combination seeding 3/synthesis A (MB_5), as shown in Fig. 7. This figure also shows that the relatively good performance of MB_2 is essentially due to the selective permeation of $n \mathrm{HEX}$. The preferential adsorption of the linear isomer together with the higher thickness of the zeolite film (considering $\sim 6 \mu \mathrm{m}$ thickness observed by SEM for MB_1) could account for the results obtained with MB_2. Especially noteworthy is the difference in separation performance of MB_5 versus MB_9 when compared with the pervaporation and permporometry results. Despite the similar degree of defects of MB_5 and MB_9, the latter is much less selective. Taking into account that the $\mathrm{Si} / \mathrm{Al}$ ratio of the synthesis solution used

Table 3

Vapour separation experiments of an equimolar mixture $n \mathrm{HEX} / 3 \mathrm{MP} / 23 \mathrm{DMB} / 22 \mathrm{DMB}$ in He as carrier gas $50 \mathrm{ml} / \mathrm{min}$; He sweep gas $50 \mathrm{ml} / \mathrm{min}$; $p_{\mathrm{mix}}=1 \mathrm{kPa}$.

\begin{tabular}{|c|c|c|c|c|c|c|c|c|}
\hline \multirow[t]{2}{*}{ Membrane } & \multirow[t]{2}{*}{ Temp. (K) } & \multirow{2}{*}{$\begin{array}{l}\text { Total isomer permeate flux } \\
\left(\times 10^{-6} \mathrm{~mol} /\left(\mathrm{m}^{2} \mathrm{~s}\right)\right)\end{array}$} & \multirow[t]{2}{*}{ Permeation fraction } & \multicolumn{4}{|c|}{ Separation factor, $S$} & \multirow[t]{2}{*}{$\Delta \mathrm{ON}^{\mathrm{a}}$} \\
\hline & & & & $3 \mathrm{MP} / 22 \mathrm{DMB}$ & 3MP/23DMB & $n$ HEX/22DMB & $n \mathrm{HEX} / 23 \mathrm{DMB}$ & \\
\hline MB_2 & 373 & 16.2 & 0.24 & 1.22 & 1.11 & 1.81 & 1.64 & +2.2 \\
\hline MB_4 & 373 & 27.2 & 0.40 & 1.38 & 1.13 & 1.69 & 1.38 & +3.7 \\
\hline MB_5 & 343 & 24.0 & 0.36 & 1.40 & 1.15 & 1.78 & 1.46 & +3.4 \\
\hline MB_5 & 373 & 25.2 & 0.38 & 1.40 & 1.17 & 1.82 & 1.52 & +3.9 \\
\hline MB_5 & 403 & 26.7 & 0.40 & 1.39 & 1.17 & 1.83 & 1.53 & +4.4 \\
\hline MB_5 & 443 & 27.5 & 0.41 & 1.46 & 1.18 & 1.88 & 1.53 & +4.7 \\
\hline MB_6 & 373 & 28.0 & 0.43 & 1.22 & 1.10 & 1.48 & 1.33 & +3.3 \\
\hline MB_9 & 373 & 27.1 & 0.39 & 1.11 & 1.04 & 1.19 & 1.11 & +1.1 \\
\hline MB_15 & 373 & 33.7 & 0.49 & 1.15 & 1.06 & 1.25 & 1.15 & +2.1 \\
\hline
\end{tabular}

a $\Delta \mathrm{ON}=\mathrm{ON}_{\text {Retentate }}-\mathrm{ON}_{\text {Feed }}$. 


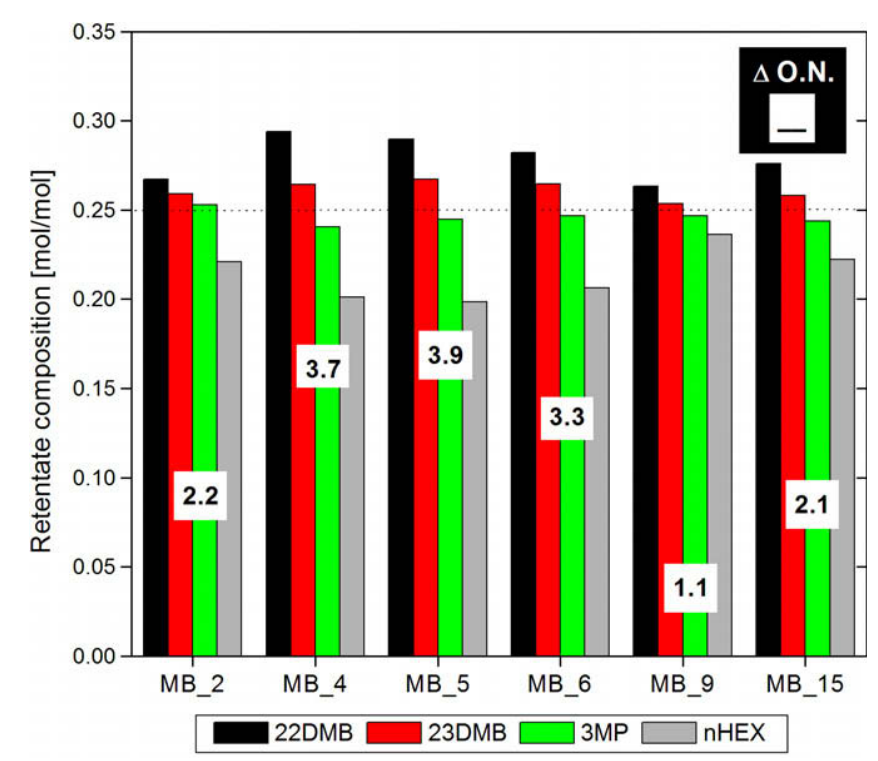

Fig. 7. Composition of the retentate 22DMB, 23DMB, 3MP and $n \mathrm{HEX}$ equimolar mixture at $T=373 \mathrm{~K}$ and $p_{\text {mix }}=1 \mathrm{kPa}$ through $\alpha-\mathrm{Al}_{2} \mathrm{O}_{3}$ supported zeolite Beta membranes.

for MB_5 is four times lower than for MB_9 (see Table 1 ), these results could indicate that the aluminium content plays a role in the separation. In a recent adsorption equilibrium study on MFI samples with different Si/Al ratio, Ferreira et al. reported [23] that the sorption affinity of hexane isomers increases with aluminium content. Jareman et al. [24] compared the hydrocarbon isomers separation performance of MFI membranes with almost identical thickness and defects distribution but different Si/Al ratio (Silicalite-1, $\mathrm{Si} / \mathrm{Al}=\infty ; \mathrm{ZSM}-5, \mathrm{Si} / \mathrm{Al}=100$ ). They found that in the range $373-473 \mathrm{~K}$ the $n \mathrm{HEX} / 22 \mathrm{DMB}$ selectivity of the Silicalite- 1 membrane was almost half of the one obtained for the ZSM-5 membrane [24].

From these permeation results combined with the permporometry results, we conclude that small defects $(<3 \mathrm{~nm})$ do not affect strongly the separation performance of the membrane, while thickness and aluminium content may have a larger impact, as apparent from comparing the performance of membranes MB_2 and MB_15 as well as MB_5 and MB_9. The presented results also show permporometry as a more convenient and informative technique to measure defects in microporous membranes than the pervaporation of ethanol/TIPB [17].

The influence of the temperature on the separation performance of membrane MB_5 was investigated by studying the vapour permeation of an equimolar hexane isomer mixture in the range 323-443 K. Permeation data and selectivity at different temperatures are presented in Table 3. The hydrocarbons permeate faster as the temperature increases, indicating the presence of an activated transport mechanism. There is a slight increase in the separation factors for membrane MB_5 with temperature up to $423 \mathrm{~K}$; the $n \mathrm{HEX} /$ dibranched separation being more temperature dependent than for the case $3 \mathrm{MP} /$ dibranched. As a result, an additional improvement of $1.3 \mathrm{ON}$ is obtained by increasing the temperature from 343 to $443 \mathrm{~K}$. This temperature dependence of the selectivity is in agreement with the results reported by Barcia et al. [11] for the fixed bed adsorption of quaternary mixtures of hexane isomers in pellets of zeolite Beta. Fig. 8 shows both the composition of the retentate stream and the ON improvement as a function of the temperature for membrane MB_5. Clearly the fraction of dibranched isomers increases with the temperature as result of a faster permeation of $n$ HEX through the zeolite film.

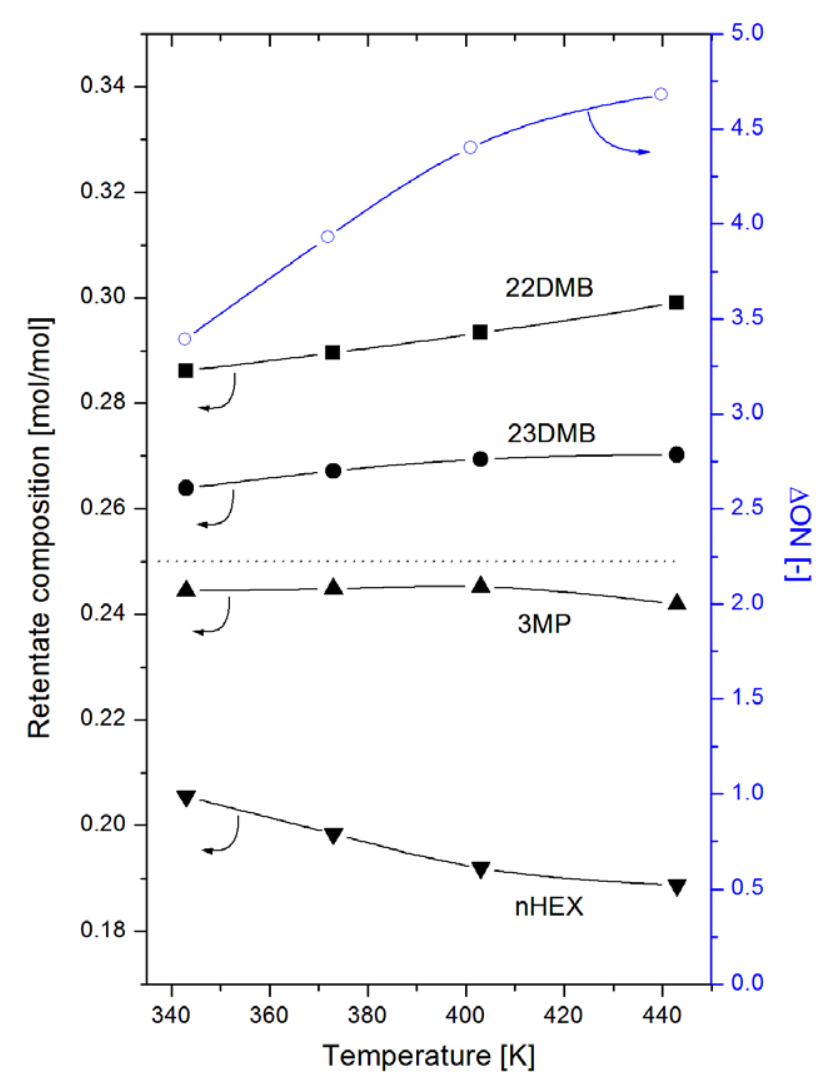

Fig. 8. Composition of the retentate stream and octane enhancement as a function of the temperature for an equimolar mixture 22DMB, 23DMB, 3MP and $n \mathrm{HEX}$ through membrane MB_5. He-carrier gas $50 \mathrm{ml} / \mathrm{min}$; He sweep gas $50 \mathrm{ml} / \mathrm{min}$; $p_{\text {mix }}=1 \mathrm{kPa}$.

The composition of the monobranched 3MP is not significantly influenced by the temperature change. Several authors [6-8] reported a significant decrease of the linear/branched selectivity as a function of the temperature for vapour permeation experiments of binary mixtures in MFI membranes. The positive selectivity/ temperature relation obtained through our zeolite Beta membrane gives more flexibility for the selection of the operating conditions required to combine such a separation technology with a hydroisomerization unit. These reaction units usually operate in the temperature range $403-423 \mathrm{~K}$ in the case of $\mathrm{Pt} / \mathrm{chlorinated}$ alumina, $453-483 \mathrm{~K}$ for sulphated metal oxide catalysts, and $523-553 \mathrm{~K}$ for Pt/zeolite based catalysts [1].

Overall, we conclude that the Beta membranes exhibit a relatively low selectivity for the targeted separation. Nevertheless this work demonstrates the octane boosting by selective permeation of linear and single branched isomers from quaternary mixtures containing linear, mono- and dibranched C6 isomers through BEA membranes.

\section{Conclusions}

Three different synthesis methods and seeding techniques for producing zeolite Beta membranes on tubular alumina supports have been studied. The surface of the membranes was completely covered by well intergrown crystals with a size distribution ranging from 0.2 to $2 \mu \mathrm{m}$ in diameter; the thickness of the zeolite layers is about $5,2.5$ and $2 \mu \mathrm{m}$ for synthesis methods $\mathrm{A}$, B and C, respectively. $\mathrm{N}_{2}$ permeation results show that synthesis method $A$ is the most effective procedure to obtain good quality membranes. The preparation duration was also considerably reduced compared to 
literature. Pervaporation experiments of a mixture ethanol/TIPB together with permporometry characterization demonstrate the low contribution of defects in most of the synthesized membranes. The vapour separation experiments at $373 \mathrm{~K}$ using a quaternary equimolar mixture of hexane isomers show that permeate flux increases as the branching degree decrease following the order: $n$ HEX " $3 \mathrm{MP}>23 \mathrm{DMB}>22 \mathrm{DMB}$. The best quality membrane MB_5 exhibited an activated transport mechanism with a stronger temperature dependency of $n \mathrm{HEX}$ and $3 \mathrm{MP}$ than the dibranched hexanes. In the retentate the fraction of dibranched isomers increases while the concentration of monobranched and normal hexane decreases compared to the feed composition. At $443 \mathrm{~K}$, the octane number $\mathrm{ON}$ can be increased by almost five points. Comparison with literature suggest that BEA performs better in the separation of mono-from dibranched C6 isomers, while MFI membranes are more effective for the separation linear/branched C6 isomers.

\section{Acknowledgments}

The X-ray facilities of the Department of Materials Science and Engineering of the Delft University of Technology are acknowledged for the X-ray analyses. Ing. J. van den Bergh is gratefully acknowledged for his help with the quaternary mixture experiments. P.S.B. acknowledges his Ph.D. scholarship by FCT (SFRH/ BD/30994/2006). J.A.C.S. acknowledges financial support provided by national research grant FCT PTDC/EQU-EQU/69731/2006 and by LSRE financing by FEDER/POCI/2010. J.G. thanks Senter Novem for financial support through the project EOSLT-04008.

\section{References}

[1] H. Weyda, E. Köhler, Catal. Today 81 (2003) 51-55.

[2] A.F.P. Ferreira, M.C. Mittelmeijer-Hazeleger, A. Bliek, Adsorption 13 (2007) $105-114$.

[3] R. Krishna, B. Smit, T.J.H. Vlugt, J. Phys. Chem. A 102 (1998) 7727-7730.

[4] S. Calero, B. Smit, R. Krishna, Phys. Chem. Chem. Phys. 3 (2001) 4390-4398

[5] C.L. Flanders, V.A. Tuan, R.D. Noble, J.L. Falconer, J. Membr. Sci. 176 (2000) 4353.

[6] S. Sommer, T. Melin, J.L. Falconer, R.D. Noble, J. Membr. Sci. 224 (2003) 51-67.

[7] L. Gora, J.C. Jansen, J. Catal. 230 (2005) 269-281.

[8] H.H. Funke, A.M. Argo, J.L. Falconer, R.D. Noble, Ind. Eng. Chem. Res. 36 (1997) 137.

[9] P.S. Bárcia, J.A.C. Silva, A.E. Rodrigues, Micropor. Mesopor. Mater. 79 (2005) 145-163.

[10] P.S. Bárcia, J.A.C. Silva, A.E. Rodrigues, Ind. Eng. Chem. Res. 45 (2006) 43164328.

[11] P.S. Bárcia, J.A.C. Silva, A.E. Rodrigues, AIChE J. 53 (2007) 1970-1981

[12] M.L. Maloncy, A.W.C. van den Berg, L. Gora, J.C. Jansen, Micropor. Mesopor. Mater. 85 (2005) 96-103.

[13] V.A. Tuan, S. Li, J.L. Falconer, R.D. Noble, Chem. Mater. 14 (2002) 489-492.

[14] M. Torres, L. López, J.M. Domínguez, A. Mantilla, G. Ferrat, M. Gutierrez, M. Maubert, Chem. Eng. J. 92 (2003) 1-6.

[15] M. Torres, M. Gutiérrez, L. López, V. Múgica, R. Gomez, J.A. Montoya, Mater. Lett. 62 (2008) 1071-1073.

[16] M.A. Camblor, A. Corma, A. Mifsud, J. Perez-Pariente, S. Valencia, Stud. Surf. Sci. Catal. 105 (1997) 341-348.

[17] N. Nishiyama, K. Ueyama, M. Matsukata, Micropor. Mater. 7 (1996) 299-308.

[18] J. Caro, M. Noack, Zeolite Micropor. Mesopor. Mater. 115 (2008) 215-233.

[19] F. Jareman, C. Andersson, J. Hedlund, Micropor. Mesopor. Mater. 79 (2005) 1-5.

[20] M.M.J. Treacy, J.B. Higgins, Collection of Simulated XRD Powder Diffraction Patterns for Zeolites, fifth ed., Elsevier, Amsterdam, 2007.

[21] C. Andersson, Factors Affecting MFI Membrane Quality, Ph.D. Thesis, Luleå University of Technology, Sweden, 2007.

[22] J.B. Lee, H. Funke, R.D. Noble, J.L. Falconer, J. Membr. Sci. 321 (2008) 309-315.

[23] A.F.P. Ferreira, M.C. Mittelmeijer-Hazeleger, A. Bliek, J.A. Moulijn, Micropor. Mesopor. Mater. 111 (2008) 171-177.

[24] F. Jareman, J. Hedlund, J. Sterte, Sep. Purif. Technol. 32 (2003) 159-163. 